\title{
A continuidade do modo de vida camponês analisado sob a ótica dos signos do moderno e do não moderno e seu papel na permanência de moradores no meio rural: estudo da comunidade rural de Linha Acre - Cândido Godói (RS)
}

Rejane Inês Kieling ${ }^{1}$

\begin{abstract}
Resumo: O processo de modernização da agricultura vem sendo responsável por profundas transformações em comunidades rurais, como a comunidade de Linha Acre, comunidades que vivenciam um esvaziamento populacional uma vez que a terra passa a ser esteira de produção em escala. Tal cenário instiga pesquisas voltadas ao desenvolvimento rural devido à urgência de encontrar-se alternativas que viabilizem a continuidade dessas comunidades. Nesse sentido, o presente artigo norteia-se pela busca de elementos que sinalizem certo enraizamento dos atores à localidade, como uma forma de trazer novos olhares sobre seu entorno e compreensão de si mesmos. $O$ olhar sugerido neste estudo se dá pela observação da presença de signos do moderno e do não moderno, que, ao se mesclarem, trazem novos significados e interpretações sobre o rural. Para alcançar tal intento, buscou-se literatura direcionada ao entendimento do moderno naquilo que ele rejeita, como as campesinidades presentes na memória do cotidiano, que são os signos do não moderno, o que comunga com vertentes que procuram compreender as relações do urbano e do rural na atualidade. Durante o período de convívio na comunidade pesquisada, foram ouvidos relatos orais que demostram, por meio da comida, das tradições e dos costumes, como estes indivíduos vêm inserindo os signos do moderno ao mesmo tempo que mantêm a memória dos antepassados.
\end{abstract}

Palavras-chave: Campesinidades. Signos do moderno e não moderno. Memória.

Abstract: The process of agricultural modernization has been responsible for profound changes in rural communities such as Linha Acre. Such communities have been experiencing depopulation as land is becoming a mass production conveyor belt. This scenario has given rise to research aimed at the rural development due to the urgency to find alternatives that could make viable the continuity of such communities. Therefore, this article is guided by the search for elements that signal certain rooting of players in the place as a way of bringing new outlooks on their surroundings and understanding of themselves. The outlook suggested herein is based on observation of the signs of the modern and of the nonmodern which, after mixing, bring about new meanings and interpretations of the rural. In order to achieve said goal, the literature on the understanding of the modern in what it rejects such as characteristics of the peasant moral order remaining in the memory of everyday life that are signs of the nonmodern, having this in common with lines of thought that seek to understand the current relationships between the urban and the rural, was reviewed. While living in the community researched, oral reports that show through food, traditions, and customs how these individuals have been introducing the signs of the modern and keeping the memory of the ancestors at the same time, were heard.

Keywords: Peasant moral order. Signs of the modern and of the nonmodern. Memory.

\footnotetext{
${ }^{1}$ Doutora em Desenvolvimento Regional. Professora da ESCOOP - Faculdade de Tecnologia do Cooperativismo (Sescoop/RS - OCERGS). rejanekieling@hotmail.com
} 


\section{Introdução}

Mesmo guardando características distintas, é inquestionável que o que se entende por rural e por urbano esteja passando por profundas transformações, que não ocorrem de forma repentina, e, sim, com a constituição de áreas de transição e contato entre esses espaços que, ao mesmo tempo que assumem novas características, fazem uso do mesmo território.

Os interesses e rotinas dos atores pertencentes aos espaços urbanos e rurais confundem-se, tornando os limites desses dois espaços imprecisos e criando condições para “[...] se pensar numa nova unidade espacial que contém, contraditoriamente, os dois espaços - o urbano e o rural - superpostos, amalgamados e intrinsecamente relacionados, razão pela qual são agora espaços urbanos/rurais" (SPOSITO, 2006, p. 122).

Indo na mesma direção, Bagli (2013, p. 97) acrescenta que a incorporação de hábitos urbanos no cotidiano do meio rural não significa, de forma alguma, homogeneizar esses espaços. Para a autora, a plasticidade do capital permite que espaços diferenciados sejam incorporados e ajustados às determinações impostas. "Pensar a urbanização total da sociedade seria pensar a homogeneização dos espaços. Estes não se homogeneízam, se fortalecem pelas suas peculiaridades".

É a partir deste tipo de reflexão que o presente artigo se debruça sobre situações percebidas no cotidiano de famílias da pequena comunidade rural de Linha Acre, situada na região Noroeste do Rio Grande do Sul, pertencente ao município de Cândido Godói. Esta comunidade, por estar passando por um visível processo de redução demográfica, desperta o interesse para pesquisas que procuram identificar elementos que possam sinalizar certo enraizamento cultural desses indivíduos.

A preocupação deste estudo reside justamente em apontar em pesquisas como a realizada em Linha Acre fatores que possam representar sustentáculos no que se refere à percepção dos moradores sobre a localidade em que vivem - ou seja, pontos que identifiquem um sentimento de pertencimento ao lugar e que, se explorados e enaltecidos em projetos que visem ao desenvolvimento dessas localidades, possam representar fatores que se materializam no desejo de permanecer nesse lugar.

O ponto explorado neste estudo é a presença do modo de vida camponês no cotidiano dessas famílias e na comunidade, modificado, certamente, por uma constante relação entre 
novos modos de vida, mas com força de permanência e transferência entre as gerações devido a essa capacidade de (re)despertar familiaridades.

Nesse sentido, a questão-problema reside em saber se a continuidade do modo vida dos antepassados pode representar um fator de permanência dos indivíduos em comunidades rurais que estão passando por um processo de esvaziamento populacional devido à inserção do modo de produção capitalista.

Assumindo-se que o meio rural guarda especificidades que o diferencia do meio urbano, e afastando peremptoriamente qualquer perspectiva que interprete as transformações pelas quais o rural vem passando como uma forma de homogeneização desses espaços, o presente estudo procurou identificar o convívio de signos do moderno e do não moderno no mesmo espaço físico, bem como os significados atribuídos pelos atores à presença do moderno misturado com suas tradições e costumes.

Os signos do não moderno, ao se entrelaçarem e se cruzarem com o moderno, certamente adquirem novos formatos, mas guardam essencialidades que permitem que os indivíduos se identifiquem pela familiaridade com o modo de vida dos seus antepassados presente na memória cotidiana. Esta familiaridade também pode ser interpretada pela presença de vínculos que se expressam por um sentimento de pertencer a determinados grupos sociais e localidades. Por isso, a relevância de introduzir observações empíricas em pesquisas que se debrucem sobre perspectivas que procuram captar e interpretar sutilezas presentes na cotidianidade dos atores e seus reflexos no coletivo.

\section{0 não moderno percebido nos lugares que o moderno rejeita}

Conforme Martins (2012, p. 19), a modernidade pode ser melhor assimilada a partir das suas contradições, ou seja, a partir daquilo que ela nega, ou do que julga não fazer parte do moderno, como a miséria, o desemprego, o subemprego e tantas outras anomalias da vida cotidiana.

a modernidade anuncia o possível, embora não o realiza. A modernidade é uma espécie de mistificação desmistificadora das imensas possibilidades de transformação humana e social que o capitalismo foi capaz de criar, mas não é capaz de realizar. Mistifica desmistificando porque põe diante da consciência de cada ser humano, e na vida cotidiana de cada um, o imenso catálogo de concepções e alternativas de vida que estão disponíveis no mercado globalizado. Basta ter os recursos para consegui-lo. 
A modernidade se expressa dessa forma pela consciência crítica do moderno, que se reflete pela denúncia de sua transitoriedade, modismo e frugalidade, características que revelam a tentativa de coisificar o homem, o que se traduz na "[...] conversão do ser humano de sujeito em objeto". Nesse sentido, a modernidade utiliza os parâmetros do (in)moderno ou ao não moderno para poder compreender-se, parâmetros que se encontram naquilo que o moderno nega, como o mundo rústico e tradicional. Para pesquisas nessa área, sua proposta é de que a questão da modernidade no Brasil seja investigada pelo "[...] modo como o moderno e os signos da modernidade são incorporados pelo popular (MARTINS, 2012, p. 21).

Utilizando-se de sua larga experiência como pesquisador, o autor supramencionado registra situações que ilustram como tais signos da modernidade se inserem no cotidiano de diferentes grupos sociais, a partir dos quais desnuda as contradições que expressam a percepção de moderno no Brasil. Em um dos exemplos apresentados, ele narra uma cena ocorrida durante uma viagem que fez entre Marabá, no Pará, e Imperatriz, no Maranhão:

\footnotetext{
$\mathrm{Na}$ longa viagem tive por companheiro um sujeito relativamente jovem que usava dia e noite óculos de sol, tipo ray-ban, como aqueles que marcaram a imagem do General MacArthur. Com espanto, vi que uma das lentes ainda tinha o selo dourado da marca do fabricante. O calor era grande e a poeira era muita. A cada intervalo de tempo, o passageiro retirava cuidadosamente os óculos e com um lenço, já sujo pelo suor e pela poeira, 'limpava' cuidadosamente as lentes de maneira a não remover o selo (MARTINS, 2012, p. 33).
}

Para Martins (2012), o cuidado desse passageiro em conservar um produto que para ele representa o moderno, mantendo-o em estado de novo, indica que a modernidade para esse sujeito se insere mais como algo a ser mostrado do que vivido. O moderno se apresenta mais como uma máscara, não possui vínculos de identidade e pertencimento.

Da mesma forma, e indo ao encontro da realidade da localidade pesquisada, pode-se pensar no termo "modernização da agricultura", utilizado como sinônimo de avanço e prosperidade no meio rural devido à utilização de tecnologias que vêm permitindo aumentos de produtividade inimagináveis se comparada com o período em que a agricultura era praticada de forma mais manual. Mas, ao considerar como esse suposto processo de modernização se deu no Brasil, concorda-se com o ponto de vista defendido por Brandão (2007). 
Para Brandão (2007), a modernização da agricultura

\begin{abstract}
se realiza bem mais no plano agrícola do que no agrário. Ela 'moderniza' formas de apropriação e de concentração da propriedade fundiária e não na direção verdadeiramente moderna. Isto é, a de uma efetiva democratização social e econômica do acesso à terra e às efetivas condições sociais e tecnológicas do trabalho com a terra. Modernizamos tecnológica e capitalisticamente a agricultura, criamos às pressas um modelo importado de agronegócio sem havermos antes procedido a uma modernização estrutural do campo (BRANDÃO, 2007, p. 47).
\end{abstract}

É interessante, portanto, pensar a modernização da agricultura a partir de sua face escondida, que são as estruturas campesinas que ficaram à margem desse processo e que guardam fragmentos de um modo de vida com características que se contrapõem ao modo de vida associado ao capitalismo. E esse pode ser um dos lugares em que a memória dos indivíduos que permaneceram residindo em comunidades como a que foi pesquisada possa contribuir para encontrar novos significados individuais e coletivos no futuro.

Para análise e compreensão do estudo realizado na comunidade rural de Linha Acre, não se fará referência às estruturas campesinas, mas a resquícios de um modo de vida com fragmentos do campesinato. Para isso, será usado o termo campesinidades, usado por que utiliza este termo ao referir-se às situações comportamentais híbridas, em que são percebidos traços tanto do empresário maximizador de resultados como do camponês que se preocupa em guardar e transmitir valores simbólicos dos seus antepassados. Para exemplificar e deixar mais clara a compreensão do termo, o autor usa o exemplo do plantation, lugar onde prevalecem relações que se aproximam mais das encontradas em empresas mercantis do que em comunidades camponesas. Mas é onde se pode constatar, segundo o autor, a existência de manifestações de campesinidades, que se expressam a partir de valores que se perpetuam no tempo e são, portanto, transmitidos entre as gerações.

É nessa perspectiva que se encontra a importância das tradições como depositárias desses valores, que se fortalecem ao vivificar o passado no presente e são responsáveis por possibilitar a permanência de uma agricultura familiar que, a despeito das mudanças pelas quais a economia global vem passando e de uma tentativa permanente de homogeneização, mantém-se enquanto unidade sólida, muito mais pela cultura que carrega do que pelo modo de produção. 
Conforme Wortmann (1990),

[...] o apego à tradição pode ser o meio de sobreviver à grande transformação: manter-se como produtor familiar em meio ao processo mais geral de proletarização ou de empobrecimento. A tradição, então, não é o passado que sobrevive no presente, mas o passado que, no presente, constrói as possibilidades do futuro (WOORTMANN, 1990, p. 17).

Com o objetivo de deixar ainda mais clara a ideia do que são campesinidades, Woortmann (1990, p. 19) narra uma situação ocorrida entre ele e um sitiante do sertão sergipano. Segundo este autor, no início da conversa, o sitiante apresenta um comportamento típico de um empresário que procura maximizar seu retorno financeiro, analisando as vantagens entre investir seu dinheiro na caderneta de poupança ou na compra de mais cabeças de gado. Se o diálogo entre os dois tivesse sido interrompido nessa primeira fase da conversa, o sitiante teria sido identificado como "um pequeno produtor maximizante, secularizado, próximo ao Homo econômicus". Contudo, no transcorrer da conversa, o sitiante expõe sua preocupação em mandar benzer o gado, sendo para ele tal procedimento uma condição necessária para o sucesso de seu empreendimento, aproximando-se nesse trecho da conversa ao Homo moralis. Dois traços distintos no mesmo indivíduo? Esse aparente paradoxo é explicado pelo autor.

\footnotetext{
O que temos, e o que parece ambíguo, é um uso da história, sua apropriação individual em duas temporalidades internalizadas, onde os tempos modernos são usados para restabelecer o tempo tradicional. Transita-se pela ordem econômica para realizar, como fim, a ordem moral e, com ela, a campesinidade. Noutro extremo, contudo os mesmos tempos modernos produzem como que um deslocamento face à tradição: o sitiante se torna negociante ou pecuarista (WORTMANN, 1990, p. 19).
}

Indo nessa mesma linha de interpretação, Brandemburg (2010), ao analisar o rural tradicional e o rural moderno, conclui que, no Brasil, coexistam as duas formas. Mesmo que as relações típicas da sociabilidade tradicional já não estejam mais presentes no cotidiano da vida rural, como o mutirão, ou outras formas de ajuda mútua, surgem outras formas de sociabilidade pautadas na valorização das tradições, mas em formatos alternativos, ou seja, ao mesmo tempo que enaltecem os costumes e as tradições trazidas dos antepassados, conectam-se ao novo, procurando identificar-se com a linguagem do moderno. Como exemplo, o autor menciona as festas comunitárias, que procuram despertar um sentimento de 
orgulho nos moradores do meio rural e servem, ao mesmo tempo, como atrativo aos citadinos que se interessam em conhecer modos de vida que se identificam mais com o natural do que com a artificialidade do meio urbano.

Para Brandão (2007, p. 39), tanto no campo como na cidade, prevalece uma racionalidade empresarial movida pela lucratividade e reprodução do capital. Palavras como competitividade e ganhos de eficiência não são mais exclusivas de ambientes urbanos. À medida que o agronegócio se expande, o meio rural incorpora essa lógica capitalista em atendimento ao mercado internacional de commodities. Visto a partir dos fundamentos econômicos, tal fenômeno poderia ser classificado simplesmente como uma nova forma de arranjo entre os agentes, que encontrariam satisfação ou bem-estar com a alocação eficiente de recursos dadas as novas condições tecnológicas e fatores de produção disponíveis. Uma visão estreita, portanto, por não considerar as transformações nas "estruturas sociais de poder, de apropriação de espaços de vida, trabalho e produção". Conforme o autor,

\footnotetext{
por toda a parte estamos envolvidos com novos termos entre a terra e o trabalho, novos conflitos, ou o aguçar dos velhos conflitos entre antigos e novos personagens rurais ou 'no campo'. Uma racionalidade centrada no lucro, na competência especializada e na competição legitimada como uma forma quase única de realização do 'progresso' quebra o que resta ainda de visões e vivências tradicionais de tempo-espaço rural e de modos de vida a que se aferram ainda os índios e os camponeses (BRANDÃO, 2007, p. 39).
}

O cerne da questão do que está demonstrado acima reside no fato de que a racionalidade do capital não atinge somente a dimensão econômica da vida, que está diretamente associada ao capital e ao trabalho, mas todas as dimensões da vida humana, que, conforme Santos (1996, p. 305), “[...] se espalham por todo corpo social, tornando-se verdadeiros regedores do tempo social".

Fazendo uma análise sobre a forma como essa racionalidade capitalista adentra no mundo rural, Santos (1996) corrobora Martins (2012), pois, se para este último o moderno é compreendido a partir de sua negação, ou seja, a partir do não moderno ou amoderno, Santos (1996) verifica que é na existência de contrarracionalidades que o ambiente rural pode ser melhor compreendido. 
Essas contrarracionalidades se localizam, de um ponto de vista social, entre os pobres, os migrantes, os excluídos, as minorias; de um ponto de vista econômico, entre as atividades marginais, tradicional ou recentemente marginalizadas; e, de um ponto de vista geográfico, nas áreas menos modernas e mais "opacas", tornadas irracionais para usos hegemônicos. Todas essas situações se definem pela sua incapacidade de subordinação completa às racionalidades dominantes, já que não dispõem dos meios para ter acesso à modernidade material contemporânea. Essa experiência da escassez é a base de uma adaptação criadora à realidade existente (SANTOS, 1996, p. 309).

Também nessa mesma linha de entendimento, Brandão (2007) cita exemplos de movimentos ou grupos sociais que se contrapõem à racionalidade ditada pelo capital, que tenta transformar espaços físicos e sociais em estruturas homogêneas. Tais grupos são representados por comunidades negras rurais quilombolas, comunidades camponesas, acampamentos sociais da reforma agrária e comunidades indígenas. Tais grupos se caracterizam por um aparente paradoxo: se, por um lado, tornam-se cativos diante do poder representado pelas estruturas do capital, por outro, sobrevivem e reproduzem suas campesinidades.

A questão que se coloca é como esses grupos sociais conseguem sobreviver ao longo do tempo? Um dos elementos que ajuda a responder a esse questionamento reside na manutenção de tradições entre as gerações. Tradições que não são transmitidas de forma formal, mas por representações simbólicas, implícitas em seu modo de vida, pensamento que é melhor explicitado por Brandão (2007, p. 55),

como costumamos dizer e relembrar sempre na antropologia, a própria economia é uma das muitas dimensões de uma cultura. Produzimos bens e vendemos trabalho e/ou mercadorias. Mas, através de pessoas e de coisas (mesmo num mundo onde pessoas têm valor como coisas e coisas, como pessoas), na verdade o que trocamos nos diferentes tempos-espaços dos diversos mercados possíveis são símbolos e significados, valores e sentidos de vida. Um mesmo pai-camponês que em novembro se endivida para comprar uma máquina duvidosa, em março duplica a dívida para não deixar de casar a filha caçula com uma 'grande festa'.

É nessa mescla constante entre o homo economics e homo moralis que se manifestam as campesinidades, por cuja presença no núcleo de famílias e comunidades pode-se compreender como o passado se mantém permanentemente vivo no modo de vida de grupos sociais do meio rural na atualidade. Nesse sentido, é importante refletir sobre a memória do modo de vida dos antepassados, presente por meio de outras formas de transmissão, não tão visíveis, mas com força de permanência entre as gerações. Para contribuir com essa reflexão, optou-se por lugares da memória que puderam ser observados na comunidade rural de Linha 
Acre: a comida, as tradições e os costumes relacionados aos componentes de etnicidade destes indivíduos e da comunidade.

\subsection{As sinalizações do não moderno e do moderno por meio da comida}

Considera-se que uma das formas mais simples de reter o modo de vida das gerações que nos precederam esteja presente nos padrões alimentares mantidos por determinados grupos de indivíduos e comunidades. A comida, conforme explica Woortmann (2013), possui uma linguagem própria, pois ela incorpora saberes que revelam muito das características das sociedades. Para a autora, o significado da comida transmite mensagens ou sinalizações sobre a construção cultural e suas representações sociais.

[...] a comida 'fala' da família, de homens e de mulheres, tanto para o pesquisador que realiza uma leitura consciente dos hábitos de comer, como para os próprios membros do grupo familiar - e através deste, da sociedade - que realizam uma prática inconsciente de um 'habitus' alimentar (WOORTMANN, 2013, p. 13).

Entre os exemplos apresentados pela autora, talvez o mais emblemático seja o fondue, comida que, atualmente, está claramente associada a grupos de indivíduos com maior poder aquisitivo, pois é servido em restaurantes que oferecem pratos mais sofisticados em seu cardápio, e requer um aprimoramento em termos de paladar e combinação de vinhos, etc. Na origem desse típico prato de dias frios, no entanto, está a pobreza.

$\mathrm{O}$ 'fondue' era originalmente uma comida preparada à noite, por grupos de pastores em abrigos escuros, no frio das montanhas. Era a sua única comida quente do dia. Tradicionalmente, cada pastor colocava no caldeirão da trempe, os restos do queijo que guardara num bolso e o pão preto que guardara no outro. Esse pão, duro, escuro, muitas vezes era preparado com sementes, cereais selvagens que nas frequentes crises de fome eram consumidas. Combinando restos de pães e queijos de diferentes vales, o 'fondue' também 'fala' de refeição compartilhada, reciprocidade e ajuda mútua, de identidades de lugares, do vale de cada camponês e das variedades de queijos da Suíça (WOORTMANN, 2013, p. 12).

A comida também "fala" de classes sociais. Thompson (1998), em seu estudo sobre a cultura popular tradicional inglesa do século 18 , usa a linguagem da comida para "falar" de representações sociais. $\mathrm{O}$ autor menciona que, durante o século em questão, a farinha branca apresentava status de comida para os ricos em detrimento das farinhas escuras, que traziam implícitas a associação de comida para os pobres, uma vez que essa farinha era o "refugo" da 
farinha branca e podia conter misturas que colocavam em risco a saúde dos trabalhadores que dependiam desse alimento para sobreviver (THOMPSON, 1998, p. 154).

Nessa mesma linha de entendimento, Wortmann (2013) usa o exemplo da Kässchmier, que é preparada com nata e creme de leite nas casas dos colonos em melhores condições de renda, que contrasta com o preparo somente com leite nas casas dos colonos pobres.

Em pesquisa realizada por Menasche (2009) com moradores do meio rural e urbano, a autora identifica na comida a existência de aspectos relacionados à identidade dos indivíduos. No que se refere às famílias do meio rural analisadas, utilizou-se o exemplo da polenta como um prato representativo da identidade das famílias de imigrantes italianos. Pôde-se concluir que, se outrora a polenta falava de escassez, pois era usada como alimento substituto ao pão, que era mais difícil estar presente na mesa das famílias mais pobres, devido ao valor da farinha de trigo, na atualidade, "fala" mais de memória no sentido de preservar hábitos alimentares no seio dessas famílias.

\footnotetext{
Atualmente, embora já não com tanta regularidade, a polenta permanece presente à mesa dessas famílias rurais e de seus descendentes. Entretanto, se antes - ainda na Itália ou nos primeiros tempos de Brasil - a polenta era a comida que, mesmo em períodos de escassez, de algum modo assegurava o necessário à manutenção desses agricultores, talvez agora possamos perceber, entre aqueles que vivem em trabalham no campo, usos de significados diversos da polenta, associados a diferentes percepções do rural e distintos processos de constituição de identidade (MENASCHE, 2009, p. 210).
}

O exemplo da polenta é também usado para se falar da rejeição ao meio rural por parte dos moradores mais jovens, sentimento mais fortemente manifestado entre as moças, que transparecem de forma mais clara o desejo de ir para a cidade em busca de outras formas de viver. Este fato foi constatado pela autora em conversa com uma jovem. A menina contava seus sonhos e desejos para a pesquisadora, e isso ocorria no turno da manhã, enquanto sua mãe preparava a refeição. De acordo com a autora, a menina "[...] franziu o nariz, fazendo cara de nojo, ao comentar a respeito do prato que a mãe preparava para nosso almoço: polenta" (MENASCHE, 2009, p. 212).

A partir da narrativa apresentada por Menasche (2009), pode-se depreender que, no alimento em questão, exista uma linguagem intrínseca relacionada aos signos do moderno e do não moderno. Nesse caso, para a menina entrevistada, a tradição mantida pela mãe traz atributos vinculados ao que ela interpreta como retrógrados ou não modernos. Já à mãe, que 
procura manter essa tradição, pode-se associar a ideia de enraizamento e valorização da memória dos antepassados. São, portanto, diferentes percepções do mesmo fenômeno por atores que fazem parte do mesmo espaço social.

2.3 Tradições e costumes: herança cultural e adaptação ao novo

Juntamente com a comida, pode-se refletir também sobre o papel das festas em comunidades rurais para revivificar as tradições e os costumes dessas localidades. Numa pesquisa sobre os costumes e tradições no Cerrado de Minas Gerais, Santos e Kinn (2009, p. 60) escolhem a festa como uma manifestação que permite analisar e compreender relações de vizinhança, de amizades, de religiosidade, bem como as diferentes redes sociais que se estabelecem nas comunidades em que ocorrem. Conforme os autores, "[...] a partir das festas, foi possível analisar as estratégias, os arranjos comunitários, fundamentados em experiências vividas individualmente e em comunidade".

Ao se falar sobre festas realizadas em comunidades rurais, é inevitável a associação imediata com os festejos religiosos em homenagem aos seus santos padroeiros, como as kerbfest, por exemplo, em localidades de colonização alemã. Com relação às festas de cunho religioso, como as kerbfest, Santos e Kinn (2009) verificam, com base em observações na localidade que pesquisaram, que a religião em si não foi o fator determinante para a construção de templos religiosos. A motivação estaria mais voltada à necessidade de estabelecer e fortalecer relações sociais, as quais tinham por objetivo principal o apelo à cooperação dos moradores para a formação da própria comunidade, além da solidificação de elos de ajuda mútua e reciprocidade, essenciais ao modo de produção então vigente.

Os costumes representam, portanto, manifestações de padrões éticos e morais desses grupos sociais. Outro elemento que se pode depreender da investigação de Santos e Kinn (2009), realizada no Cerrado de Minas Gerais, está relacionado à formação de laços de confiança entre as pessoas: indivíduos que participam das atividades realizadas na comunidade, que se engajam e valorizam os costumes locais, são respeitados. Tais elos se estendem, evidentemente, às relações de trabalho, uma vez que a mesma pessoa que é vista com respeito por sua participação na vida comunitária também é identificada, via de regra, como alguém que tem devoção ao trabalho, sendo essa uma das características mais 
valorizadas em comunidades rurais como a comunidade rural de Linha Acre, conforme pôde ser verificado nos relatos dos moradores.

Refletindo sobre a constante interação ente o passado e o presente, Santos (2013) aponta o papel das tradições como elo entre as gerações, devido a sua capacidade para transmitir saberes de forma espontânea, ou seja, sem que os indivíduos se deem conta disso. Tradição e memória se complementariam. Mesmo que o moderno, como visto em Martins (2012), associe tradição a algo retrógrado, é o fato de reconhecer-se na cultura herdada que permite o desenvolvimento constante do sentimento de pertencimento, pois, segundo Santos (2013), o que é transmitido por nossos antepassados não é algo estranho a nós. O passado teria ressonância nos indivíduos porque é o espelho no qual nós nos reconhecemos.

É nessa linha de entendimento e interpretação que se percebe a relevância de adentrar em camadas mais sutis das percepções e vivências dos indivíduos. Para atingir tal intento, procurou-se identificar, na comunidade rural pesquisada, como esses atores significam a continuidade da própria localidade em que nasceram e vivem a partir dessa constante mescla entre o moderno e o não moderno, o que, de certa forma, está associado a um sentimento de pertencimento ao lugar devido à familiaridade de determinados hábitos e costumes relacionados ao modo de vida dos antepassados presentes em sua cotidianidade.

\section{Procedimentos metodológicos}

O presente artigo faz parte de pesquisa realizada para tese de doutorado titulada "(Re)significados do rural: estudo da memória dos agricultores sobre o processo de modernização da agricultura na comunidade rural de Linha Acre, Cândido Godói (RS)".

A pesquisa junto à comunidade rural de Linha Acre foi realizada durante os anos de 2016 e 2017, em períodos de convívio com os moradores, em que foi possível captar as sutilezas que envolvem a identificação do modo de vida dos antepassados presente nas manifestações da memória individual e coletiva dessa comunidade. Para os registros mnemônicos dos entrevistados, bem como suas percepções sobre as transformações da vida comunitária, foi utilizada como metodologia a história de vida. E, como técnica para coleta de dados, para se obterem os relatos orais, foi utilizada a história oral com o auxílio de questões norteadoras. 
Ao longo do período destinado à coleta de dados, foram realizadas visitas à comunidade estudada, totalizando 24 entrevistas, divididas em três públicos de interesse: idosos, produtores tradicionais e produtores tradicionais que fazem parte do grupo de produção orgânica, desenvolvido pela Emater/RS-Ascar. Para fins de apresentação dos relatos orais dos entrevistados, estes foram classificados da seguinte forma: IDOSO(A) - Grupos 1, 2 e 3 - divididos conforme classificação do Instituto de Pesquisa Econômica Aplicada (IPEA) Grupo 1: idosos jovens, pessoas que têm entre 60 e 70 anos de idade; Grupo 2: medianamente idosos, pessoas a partir de 70 até 80 anos de idade; e Grupo 3: muito idosos acima de 80 anos; TRADICIONAL(agricultores que se dedicam exclusivamente à produção de grãos e leite) e TRADICIONAL/ORGÂNICO (agricultores que se dedicam à produção de grãos e leite, mas fazem parte do grupo de orgânicos).

Os produtores tradicionais, separados em grupo específico de análise, são indivíduos que não fazem parte do projeto de orgânicos, e o grupo específico denominado Tradicional/Orgânico é composto por produtores que exercem as duas formas de atividade rural, aos quais foram direcionadas questões tanto da produção tradicional de grãos e leite como as que são relacionadas ao projeto de orgânicos.

\section{Os signos do não moderno e do moderno percebidos na comunidade rural de Linha Acre}

Para melhor compreender a percepção dos atores sobre o lugar em que nasceram e vivem, bem como a presença e valorização de vínculos com o modo de vida dos antepassados, considerados nesta pesquisa como uma das razões que explica a permanência destes na comunidade, julga-se apropriado iniciar esta seção com alguns pontos relacionados ao início da comunidade rural de Linha Acre.

A origem da comunidade rural de Linha Acre está ligada ao processo de deslocamento dos imigrantes alemães e seus descendentes das "colônias velhas" para a região Noroeste do Estado do Rio Grande do Sul, onde se instalaram provisoriamente na colônia Serro Azul ${ }^{2}$ (atual

\footnotetext{
2 Serro Azul é atualmente conhecida como Cerro Largo. Teve seu nome modificado após imposição do IBGE, que, em 1942, exigiu que a troca de seu nome para poder se emancipar (RAMOS, 2006, p. 43).
} 
Município de Cerro Largo), que fora fundada em 1902 por uma comissão liderada pelo padre Maximiliano Kuno Maria Von Lassberg.

Um processo de colonização não se restringe, certamente, a aspectos de formação territorial, deslocamento geográfico e transformações de ordem econômica. Deve ser compreendido e significado a partir da totalidade do que representa a inserção cultural desses indivíduos (no caso, imigrantes alemães) no território de destino. No contexto da formação das "colônias novas" significou, além das questões de ordem econômica e de povoamento, a intenção de manter a cultura alemã fortalecida no seio desses grupos sociais, o que significa dizer, em outros termos, que tenha havido claro intuito de homogeneização cultural.

Os autores Lando e Barros (1976) explicam que, em termos práticos, essas colônias ou comunidades tiveram dificuldades para se integrar. O principal empecilho para a integração dos imigrantes deveu-se ao isolamento das colônias alemãs. O isolamento geográfico deu-se em virtude da precariedade nas vias de acesso e comunicação, mas também se pode visualizar a existência de um isolamento cultural protetório das raízes que vinculavam esses imigrantes ao país de origem.

Há de se considerar que a bagagem social e cultural trazida pelos colonos oriundos da Europa foi imprimindo seu modo de vida no território rio-grandense. É importante frisar que, ao se falar em território, o conceito utilizado é o que associa território ao uso que dele os atores fazem, conforme explicam Santos e Silveira (2001, p. 21):

\footnotetext{
o uso do território pode ser definido pela implantação de infraestruturas, para as quais estamos igualmente utilizando a denominação de engenharia, mas também pelo dinamismo da economia e da sociedade. São os movimentos da população, a distribuição da agricultura, da indústria e dos serviços, o arcabouço normativo, incluídas a legislação civil, fiscal e financeira, que, juntamente com o alcance e a extensão da cidadania, configuram as funções do novo espaço geográfico.
}

Essa visualização do território permite extrapolar as barreias impostas pela limitação geográfica e demonstrar que “[...] se podemos entender o território como extensão apropriada e usada, territorialidade pode ser definida como o sentido de pertencer àquilo que nos pertence", compreendendo pertencimento não necessariamente como posse ou propriedade, mas a apropriação que os indivíduos e grupos sociais percebem em relação àquele espaço. Essa percepção é compreendida como um conjunto de práticas e expressões materiais e simbólicas que se vinculam a atributos tais como raça, religião, sexo, idade, entre outros (SILVEIRA, 2013, p. 39). 
Nessa mesma linda de entendimento, Etges e Degrandi (2013, p. 7) ensinam que “[...] é fundamental compreender que à medida em que a sociedade vai se apropriando de determinado território, ela vai imprimindo as suas marcas", ou seja, são as formas impressas no território que desnudam como esse território vem sendo usado.

A partir desse entendimento, a presente pesquisa procurou captar a presença do enraizamento de alguns componentes relacionados tanto à etnicidade dos atores como ao modo de vida mais associado ao campesinato ou campesinidades, como já fora mencionado anteriormente.

Ao serem questionados sobre como percebem as mudanças advindas com o processo de modernização da agricultura, sob o ponto de vista econômico, foi constatado visível entusiasmo em função, principalmente, do menor desgaste físico e a possibilidade de aferirem mais renda. Ao serem instigados a pensar nos efeitos desse mesmo processo na vida social da comunidade, o brilho no olhar imediatamente foi substituído por um ar carregado de dúvidas e incertezas no que se relaciona ao futuro de Linha Acre. Apesar de conseguirem elencar alguns pontos positivos da comunidade, temem pelo seu esvaziamento face ao inegável êxodo protagonizado por dois extremos: os idosos e os jovens.

Esse aparente paradoxo verificado entre os entrevistados, que enxergam pontos positivos e negativos em relação ao mesmo fenômeno vivenciado, comunga com a perspectiva defendida por Wanderley (2009), que atribui aos agricultores familiares uma identidade híbrida, que se explica pelo fato de que, ao mesmo tempo em que a inserção tecnológica os coloca dentro de uma lógica global de produção de commodities, guarda um modo de vida que, segundo essa autora, só pode ser compreendido se for levada em consideração sua origem dentro do campesinato; afastando, portanto, interpretações do rural pautadas no seu desaparecimento a partir de um transbordamento do modo de vida urbano no meio rural. É, portanto, dentro desse tipo de compreensão que, na sequência, serão apresentados aspectos vinculados a esse comportamento híbrido.

\subsection{O rural e o urbano: "coisa de colono" e "coisa da cidade"}

O que instiga na visualização dos atores sobre a localidade é pensar que, mesmo que tenha havido clara redução da quantidade de habitantes, e considerando ainda que o 
dinamismo da comunidade não seja mais como no passado, atualmente, existe uma percepção positiva dos moradores a respeito da interação com o meio urbano e outras localidades. Segundo o entrevistado Tradicional 3: "Antigamente a Linha Acre necessitava ter comércio local e outros tipos de estabelecimentos; primeiro, porque havia mais moradores, e, segundo, porque o acesso a outras localidades era muito difícil". Com relação aos dias atuais, foi possível registrar os seguintes pontos positivos em relação à interação e à locomoção dos moradores: a. as estradas não são mais tão ruins; b. todas as famílias possuem automóveis; c. a interatividade virtual, que coloca os moradores do meio rural em iguais condições de acesso em relação aos citadinos. Como pôde ser observado durante as visitas, com exceção de duas residências, uma onde mora um casal de idosos, e outra onde reside uma idosa, todas as moradias tinham aparelhos como notebooks, tablets, smart tvs, celulares com tecnologia atualizada e acesso à internet com sinal de ótima qualidade.

Mesmo sem poder afirmar que tal realidade seja igual para todas as famílias de Linha Acre, pois se trata de uma amostra que representa em torno de $11 \%$ da população, pode-se perceber que são representações da modernidade que se inserem no meio rural. Somadas à racionalidade econômica, ligada às novas formas de condução da atividade agrícola pósmodernização da agricultura, elas modificam gradativamente o comportamento dos indivíduos. Tais mudanças estão diretamente relacionadas ao processo de globalização, que, de acordo com Hall (2014, p. 49),

refere-se àqueles processos, atuantes numa escala global, que atravessam fronteiras nacionais, integrando e conectando comunidades e organizações em novas combinações de espaço-tempo, tornando o mundo, em realidade e em experiência, mais interconectadas.

Essas novas relações não significam que haja subordinação do rural ao urbano. Ao contrário disso, para estes entrevistados o uso de tecnologias não está associado a algo que seja da "cidade", mas, sim, a algo em que estão incluídos. Reitera-se, portanto, que o que foi possível observar na comunidade rural de Linha Acre, e inclusive entre os moradores mais jovens, é uma constante mescla entre as características mais ligadas ao rural com as que se assemelham mais com o meio urbano, impossibilitando delimitar espaços que os pudessem separar. Isso fica ainda mais evidente se for levado em consideração que a população residente no centro urbano do Município de Cândido Godói, em sua grande maioria, é originária do meio rural. 
A título de ilustração dessa inter-relação entre o rural e o urbano, e indo na mesma direção defendida por Martins (2012) a respeito da compreensão do moderno a partir daquilo que ele nega, que são os parâmetros do não moderno, pode-se usar o que foi observado pela autora desta tese ao participar de bailes na região da Grande Santa Rosa voltados ao público mais jovem: são bailes em que o público é atraído por bandas conhecidas na região, cujas músicas são as mais solicitadas nas rádios locais. No fundo do palco, são apresentados videoclipes da banda, cujos integrantes usam roupas "estilosas" e fazem performances arrojadas; exacerbando, portanto, os signos da modernidade. Os jovens se divertem parados na pista de dança, bebendo e rindo, mas não dançam sozinhos, pois não parecem à vontade para isso. No decorrer da noite, quando a banda começa a tocar músicas do "estilo antigo", são elas que mais causam efeito, pois aí os jovens cantam e dançam em pares. Contudo, como comentado por alguns jovens, se no cartaz fosse apresentado um baile com músicas "estilo antigo", este seria associado a "baile de velhos" ou "coisa de colono", e esses jovens não iriam, o que denota que, ao mesmo tempo em que existe rejeição às representações do rural, ainda permanece um sentimento de familiaridade em relação à tradição que é passada de geração em geração.

4. 2 O moderno e não moderno na comida, nos costumes e nas tradições

Conforme relato da entrevistada Tradicional/Orgânico 3, o formato das festas realizadas no Clube Bom Sucesso da comunidade rural de Linha Acre vem se mantendo de forma muito parecida com o do passado. Por se tratar de famílias católicas, as festas mais comuns são de primeira eucaristia e de bodas. Antes da festa, é realizada uma celebração religiosa, e, depois, os convidados seguem para o clube. Ainda existe a divisão de tarefas entre os membros da comunidade, o que denota a presença de práticas de ajuda mútua e reciprocidade, pois quem é convidado deve convidar. Mas a entrevistada diz que já estão começando a terceirizar os serviços de organização de festas, como vem ocorrendo no meio urbano, o que, na opinião dela, talvez seja uma tendência para o futuro na comunidade.

A comida servida nessas festas, entretanto, não teria sofrido muitas mudanças ao longo do tempo. O buffet é composto por saladas variadas, temperadas com vinagre e sal, sendo que não pode faltar a salada de batatas (Kartoffelsalat). Os pratos quentes normalmente são arroz 
branco, massa, mandioca e carne de churrasco, e, também, são oferecidas fatias de cuca, lembrando os bailes dos antepassados, em que era servida cuca com linguiça.

É possível, portanto, perceber a manutenção de alguns hábitos dos imigrantes alemães e algumas adaptações à culinária regional, numa constante interação entre diferentes culturas. Conforme explica Friedrich (2015), alguns alimentos que faziam parte da rotina alimentar dos imigrantes foram totalmente incorporados pelos brasileiros. Um exemplo típico é a Kartoffelsalat (salada de batatas), cujo modo de preparo consta em registros de cadernos de receitas da Alemanha com data de 1454, ensinando a tradicional salada de maionese feita com batatas, cebolas, pepino, vinagre, sal e ovos. Atualmente, pode-se dizer que seja um complemento obrigatório do churrasco, que é um prato tipicamente gaúcho e que foi totalmente incorporado pelos descendentes de alemães, sendo classificado pelos entrevistados como "uma comida de domingos e de dias de festa". Assim também a mandioca, mais uma "comida de dia de semana", que, de acordo com Neto (2007, p. 236), teria sido introduzida no cardápio dos teuto-brasileiros desde o momento em que conheceram esta espécie nativa. "A expressividade do aipim, mais conhecido no Rio Grande do Sul como mandioca, salientou-se no decorrer do desenvolvimento das colônias alemãs gaúchas". Observou-se que essa raiz é plantada para o consumo das famílias até mesmo em residências do meio urbano, no Munícipio de Cândido Godói, compondo as variedades de produtos plantados para o seu autoconsumo.

Os entrevistados também foram convidados a recordar atividades que envolvem comemorações relativas a datas, como Natal, Páscoa e Ano Novo. Durante suas narrativas, foi possível perceber que experimentaram o retorno a lugares da memória, tanto do ambiente interno de suas casas como da comunidade em que vivem, numa constante troca entre a memória individual e a coletiva.

Tomando como base os ensinamentos de Bosi (2013), buscou-se, primeiramente, conhecer a memória dos atores, seguindo por caminhos familiares, oriundos das lembranças de infância das datas comemorativas mencionadas acima. O Natal e a Páscoa foram as datas em que os entrevistados mais deixaram transparecer um sentimento de saudades. Lembradas primeiramente pelo sabor dos doces que ganhavam dos padrinhos e madrinhas, que eles denominam de packche (presentinho). Havia, segundo eles, todo um ritual que envolvia o ato de buscar esses presentes. 
Para uma das entrevistadas, a lembrança da Páscoa lhe trouxe até mesmo a sensação da felicidade que sentia quando era criança e via sua mãe juntando cascas de ovos de galinha para serem limpas e depois preenchidas com amendoim doce. Lembrou, ainda, como eram os presentes que seu pai dizia receber e como era na época da infância dela:

\begin{abstract}
Meu pai sempre contava que, quando ele era pequeno, eles ganhavam ovos cozidos coloridos na Páscoa, tinham que comer logo pra não estragar. Na minha época, a gente ganhava essas casquinhas de ovo coloridas com amendoim dentro, também bolachas em formato de coelho e uns doces de puro açúcar, que também eram em formato de coelhos, mas eram coloridos, isso que era especial pra nós. Hoje as crianças não iriam gostar disso. Mas pra nós era algo muito gostoso, e nós ainda comentávamos com as outras crianças o que cada um tinha ganhado no seu 'packche' ${ }^{3}$ (IDOSA 7GRUPO 2).
\end{abstract}

Segundo os entrevistados, esse hábito de buscar os presentes nos padrinhos e madrinhas ainda se mantém de certa forma, mas com variações: "Se for perto, os afilhados até buscam o presente, mas não como nós, que íamos a cavalo para buscar. Hoje eles não querem qualquer coisa, doces nem dão mais tanto valor, porque têm mais vezes no ano" (TRADICIONAL/ORGÂNICO 3).

Os caminhos familiares da infância também conduziram a reminiscências ${ }^{4}$ das brincadeiras que eram proporcionadas nesses dias festivos. A data do Kerb também é lembrada como um momento em que era possível brincar com os parentes, que podiam visitar, ou receber visitas nessas datas. Tanto os meninos como as meninas tinham de fazer seus próprios brinquedos. Com relação aos brinquedos dos meninos, o entrevistado Tradicional/Orgânicos 2 lembra,

Era carretinha feita com carretel de linha, e, com isso, nós fabricava [sic] nossos carrinhos pra descer cerro abaixo e nos potreiros; domingo de tarde nós tava lá e, às vezes, virava esses troços e rolava três ou quatro num monte. Também ia caçar passarinhos, pescar, tudo tinha mais sentido do que pra essa criançada de hoje. Assim também, quando a gente ganhava uma bolita, Deus o livre, né? Hoje tudo tem que ser com controle remoto, se não, não querem. Naquele tempo, tudo era motivo para brincadeira (TRADICIONAL/ORGÂNICO 2).

\footnotetext{
3 Conforme Germany Travel (2012, p. 2): “Trocar ovos cozidos pintados à mão já foi parte da tradição de Páscoa no mundo todo, antes da introdução dos ovos de chocolate. Na Alemanha, porém, esta tradição resiste ao lado das guloseimas. No domingo de Páscoa, ovos cozidos com cascas pintadas são espalhados pelo jardim para serem encontrados pelas crianças".

${ }^{4}$ Termo usado neste texto no sentido de imagem lembrada do passado ou o que se conserva na memória.
} 
E sobre os brinquedos das meninas, a entrevistada Tradicional/Orgânico 4 deu o seguinte depoimento:

Nós tínhamos bonecas de pano, que a mãe mandava fazer, ou a gente enrolava o pano num sabugo ou outra coisa, e daí a gente levava no potreiro; aí nós fazíamos as nossas casas com pedacinhos de graveto, aí dividia o quarto, a cozinha e a entrada. Era tudo limpinho e organizado.

No que diz respeito à comemoração do Ano Novo, os entrevistados consideram que, no meio urbano, em cidades grandes como Porto Alegre, essa data seja comemorada de forma diferente do que em Linha Acre. Uma das diferenças mencionadas seria o uso de roupas com determinadas cores, que simbolizam desejos que as pessoas pretendem realizar no ano que inicia. Contudo, nos hábitos alimentares, percebem-se algumas adaptações, como o consumo da lentilha, que alguns entrevistados mencionaram como usual nessa data. Mas a maioria não tem o costume de fazer a ceia da virada do ano, mantendo o hábito de celebrar o novo ano no seu primeiro dia, num almoço em família, aí, sim, com mesa farta, bebidas e mesa de doces servida no meio da tarde. Conforme um dos entrevistados, um costume que é mantido é o de tocar o sino, cujo som anunciaria o ano que começa:

Aqui na Linha Acre ainda é mantido o costume de puxar o sino antes e depois da meianoite, mas isso também foi mudando com o tempo. Antigamente os jovens se reuniam e faziam uma festa de noite lá, daí se revezavam para puxar o sino uma hora antes e uma hora depois, duas horas se puxavam o sino direto, e daí depois caiu pra 15 minutos antes e 15 depois. Só nos dois últimos anos, por causa de condições climáticas, isso não foi feito, mas devem continuar fazendo (TRADICIONAL/ORGâNICO 1).

Ainda com relação às comemorações do Ano Novo, um fato interessante que todos os entrevistados lembraram, mesmo sem terem vivenciado isso diretamente, foram as brincadeiras realizadas na comunidade, por volta da década de 1960 . Eram inspiradas no Terno de Reis (tradição de origem portuguesa), realizadas por rapazes, moradores de Linha Acre, que se vestiam com roupas femininas e usavam perucas feitas com pelo de ovelha, fato que é lembrado aos risos pelos depoentes, pois, segundo eles, fazer essas perucas era o que dava mais trabalho. Na virada do ano, eles visitavam algumas casas da comunidade, anunciavam que estavam chegando, fazendo barulho com os instrumentos musicais, e eram recebidos pelos donos da casa. Um dos rapazes declamava uma poesia em alemão, agradecendo o ano que passou e desejando muita sorte para o ano que estava iniciando. 
Então eles eram convidados para entrar na casa, cantavam e dançavam com a família, que Ihes oferecia comida e bebida. Despediam-se alegremente e visitavam a casa seguinte.

O sentimento deste entrevistado em relação a não continuidade dessa tradição na Linha Acre é de tristeza, por considerar que era uma forma de integrar a comunidade, fortalecendo laços de amizade que, na atualidade, segundo ele, estão cada vez mais fragilizados devido a uma maior interferência de um modo de vida mais associado ao urbano, em que as pessoas se tornam mais individualistas.

Apesar de ter-se constatado que algumas tradições tenham se perdido totalmente com o passar do tempo, foi possível verificar-se que, no cotidiano das famílias e da comunidade, resiste o modo de vida dos antepassados. Essa resistência justifica-se pela valorização que esses atores demonstram pela preservação de hábitos, costumes e tradições, que, inseridos em seu convívio diário, trazem o passado para o presente, revivificando a memória daqueles que os precederam e, ao mesmo tempo, inserindo as novas percepções da vida moderna.

\section{Considerações finais}

O objetivo do presente artigo foi o de verificar, durante o período de convívio com moradores da comunidade rural de Linha Acre, a presença de signos relacionados ao moderno convivendo com os signos do não moderno, a fim de fornecer elementos que possam contribuir para pesquisas que estejam alicerçadas em construções protagonizadas pelos atores, adentrando-se, portanto, em camadas mais sutis das percepções e vivências desses indivíduos, que se manifestam por meio da memória presente em seu cotidiano, como na comida, nas tradições e nos costumes.

O caso da comunidade rural de Linha Acre é um entre tantos outros que estão passando pelo mesmo processo de inserção cada vez mais acirrada de produção de commodities, modificando a paisagem destas localidades. Onde, no passado, existiam casas e pessoas, na atualidade, são vistas extensões de terras que se revezam no plantio de grãos, conforme a época do ano.

Esse modo de produzir foi inserindo também novas relações, abrindo espaço para uma mentalidade mais capitalista, em que produtores familiares foram adquirindo um jeito mais 
próximo ao de empresários maximizadores de resultados. Numa visão mais apressada, poderse-ia concluir que esses indivíduos estariam migrando para um modo de vida mais urbano com a inserção de signos do moderno no cotidiano dessas famílias, e o modo de vida associado ao rural estaria desaparecendo.

Contudo, o convívio na comunidade permitiu observar-se a existência de um comportamento híbrido entre os entrevistados. Ao mesmo tempo em que introduziram uma mentalidade mais empresarial e se sentem inseridos nos padrões de convívio social considerados modernos, como as redes sociais, por exemplo, mantêm a memória viva dos seus antepassados por meio de costumes e tradições que, mesmo não perceptíveis para eles, podem significar uma força de resistência desta comunidade.

O ponto principal explorado nesta pesquisa residiu na procura por campesinidades presentes no comportamento dos indivíduos, as quais se expressam por atitudes que denotam a valorização de laços de proximidade como o espírito de comunidade e a manutenção de valores transmitidos pelos antepassados; diferenciando-se, portanto, da estrutura "coisificada" imposta pelo capitalismo. São, portanto, especificidades que devem ser levadas em consideração para que estes atores encontrem novos significados para o território a que sentem pertencer.

\section{Referências}

BAGLI, Priscila. Rural e urbano: harmonia e conflito na cadência da contradição. In: SPOSITO, Maria Encarnação Beltrão; WHITACKER, Arthur Magon (Orgs.). Cidade e campo: relações e contradições entre urbano e rural, v. 1, p. 81-109, 2013.

BOSI, Ecléa. O tempo vivo da memória: ensaios de psicologia social. 3. ed. São Paulo: Ateliê Editorial, 2013.

BRANDÃO, Carlos Rodrigues. Tempos e espaços nos mundos rurais do Brasil. RURIS, v. 1, n.1, março de 2007. Disponível em: <https://edisciplinas.usp.br/pluginfile.php/310076/ mod_resource/content/0/Brand\%C3\%A3o_Carlos.pdf>. Acesso em: 20 nov. 2015.

BRANDEMBURG, Alfio. Do rural tradicional ao rural socioambiental. Ambiente \& Sociedade, Campinas. V. XIII, n. 2, jul./dez. 2010, p. 417-428. Disponível em:

<https://core.ac.uk/download/pdf/18337780.pdf>. Acesso em: 15 jul. 2015. 
ETGES, Virginia Elisabeta; DEGRANDI, José Odim. Desenvolvimento regional: a diversidade regional como potencialidade. RBDR, Blumenau, v. 1, n. 1, p. 85-94, 2013.

FRIEDRICH, Fabiana Helma. Gastronomia e imigração alemã na região central do Rio Grande do Sul: colônia de Santo Ângelo (segunda metade do século XIX). 2015. 152f. Dissertação de Mestrado (Programa de Pós-Graduação em História) - Universidade Federal de Santa Maria, Santa Maria, 2015.

GERMANY TRAVEL. A tradição alemã da Páscoa. 2012. Disponível em: <https://www.germany.travel/media/content/presse/br/2012_6/PR_A_Tradio_Alem_da_Ps coa.pdf $>$. Acesso em: 16 set. 2017.

HALL, Stuart. A identidade cultural na Pós-Modernidade. Rio de Janeiro: Lamparina, 2014.

LANDO, Aldair Marli; BARROS, Eliane Cruxên. A colonização alemã no Rio Grande do Sul: uma interpretação sociológica. Porto Alegre: Movimento/IEL, 1976.

MARTINS, José de Souza. A sociabilidade do homem simples: cotidiano e história na modernidade anômala. São Paulo: Contexto, 2012.

MENASCHE, Renata. Campo e cidade, comida e imaginário: percepções do rural à mesa. RURIS-Revista do Centro de Estudos Rurais-UNICAMP, v. 3, n. 2, 2009.

NETO, Helena Brum. Regiões culturais: a construção de identidades culturais no Rio Grande do Sul e sua manifestação na paisagem gaúcha. 328f. Dissertação de Mestrado (Programa de Pós-Graduação em Geografia e Geociências) - Universidade Federal de Santa Maria, Santa Maria, 2007.

RAMOS, A. D. A formação histórica dos municípios da Região das Missões do Brasil. Santo Ângelo: Instituto Andaluz del Patrimonio Historico, Instituto do Patrimônio Histórico e Artístico do Patrimônio Nacional, Universidade Regional Integrada do Alto Uruguai e das Missões, 2006.

SANTOS, Milton. A natureza do espaço - técnica e tempo, razão e emoção. São Paulo: Hucitec, 1996.

SANTOS, Milton; SILVEIRA, María Laura. O Brasil Território e Sociedade no início do século $X X I$. 17. Rio de Janeiro: Record, 2001.

SANTOS, Myrian Sepúlveda dos. Memória coletiva, trauma e cultura: um debate. Revista USP, n. 98, p. 51-68, 2013.

SANTOS, Rosselvelt José; KINN, Marli Graniel. Festas: Tradições reinventadas nos espaços rurais dos cerrados de Minas Gerais. Espaço e Cultura. UERJ, Rio de Janeiro, n. 26, p. 58-71, jul./dez. de 2009. Disponível em: <http://www.e-publicacoes.uerj.br/index.php/ espacoecultura/article/view/3555>. Acesso em: 4 maio 2016. 
SILVEIRA, María Laura. Novos aconteceres, novas territorialidades. In: DIAS, Leila Christina; FERRARI, Maristela (Orgs). Territorialidades Humanas e Redes Sociais. 2. Florianópolis: Insular, 2013. p. 39-62.

SPOSITO, Maria Encarnação Beltrão. A questão cidade-campo: perspectivas a parir da cidade. In: SPOSITO, Maria Encarnação Beltrão; WHITACKER, Arthur Magon (Orgs.). Cidade e campo: relações e contradições entre urbano e rural. São Paulo: Expressão Popular, 2006. p. 111-130.

THOMPSON, Edward Palmer. Costumes em Comum: estudos sobre a cultura popular tradicional. São Paulo: Companhia das Letras, 1998.

WANDERLEY. Maria de Nazareth Baudel. O Mundo Rural como um espaço de vida: reflexões sobre a propriedade da terra, agricultura familiar e ruralidade. Porto Alegre: UFRGS, 2009.

WOORTMANN, Ellen F. A comida como linguagem. Habitus, v. 11, n. 1, p. 5-17, 2013. Disponível em: <http://seer.pucgoias.edu.br/index.php/habitus/article/view/2844>. Acesso em: 22 mar. 2017.

WOORTMANN, K. Com parente não se 'neguceia'. O campesinato como ordem moral. Anuário antropológico/87. Brasília: UnB, 1990. 